\title{
Examining achievement goals in exercisers: adaptation and validation of the goal orientations in exercise measure (GOEM)
}

\author{
Luis Cid ${ }^{1,2}$. Filipe Rodrigues ${ }^{1,2,3} \cdot$ Diogo S. Teixeira $^{4,5} \cdot$ Verónica Morales-Sánchez ${ }^{6}$. \\ Rita Macedo ${ }^{7} \cdot$ Diogo Monteiro ${ }^{1,2}$ (D)
}

(c) Springer Nature B.V. 2020

\begin{abstract}
The different criteria by which individuals evaluate their competence and define the success (or failure) of their participation in exercise is a topic of interest. The present study aimed to translate and validate the Goal Orientation in Exercise Measure (GOEM) in a sample of Portuguese exercisers. Confirmatory factor analysis and multigroup analyses were developed in order to test the factor structure and measurement invariance of the measure, respectively. The present sample comprised 550 gym and health club exercisers (female $\left.=264 ; M_{\text {age }}=30.03 \pm 10.20\right)$, with an attendance of 3.06 times $(S D=1.08)$ per week, and a mean exercise experience of 37.63 months $(S D=2.37)$. Current results showed that the measurement model of the GOEM presented adequate fit (total sample model: $\chi^{2}=108.65, \mathrm{df}=34, \mathrm{~B}-\mathrm{S} \mathrm{p}=<.001, \mathrm{SRMR}=.045$, TLI $=.960, \mathrm{CFI}=.970$, RMSEA =.060). Additionally, measurement invariance was achieved between genders and across different fitness activities. Present results showed that the predictive validity criterion was respected, since task-orientation positively and significantly predicted identified regulation $(\beta=.54)$ and intrinsic motivation $(\beta=.43)$, whereas ego-orientation was positively associated with external regulation $(\beta=.46)$ and amotivation $(\beta=.39)$. Present findings support the use of the measure for task and ego-orientation assessment, thus allowing further support for the Achievement Goal Theory framework expansion in gym and health clubs research.
\end{abstract}

Diogo Monteiro

diogomonteiro@esdrm.ipsantarem.pt

1 Sport Science School of Rio Maior (ESDRM -IPSantarém), Av. Dr. Mário Soares, 2040-413 Rio Maior, Portugal

2 Research Center in Sport Sciences, Health and Human Development (CIDESD), Vila Real, Portugal

3 Life Quality Research Center (CIEQV), Santarém, Portugal

4 FEFD/ULHT), Lusófona University, Lisbon, Portugal

5 Center for the Study of Human Performance (CIPER), Lisbon, Portugal

6 Faculty of Psychology, University of Malaga, Malaga, Spain

7 Center for Organizational and Social Studies of P. PORTO, (CEOS.PP P. PORTO), Porto, Portugal 
Keywords Achievement goals $\cdot$ Exercise $\cdot$ Psychological assessment $\cdot$ Multigroup analysis

\section{Introduction}

Achievement Goal Theory (AGT; Nicholls 1984, 1989) is based on the existence of two groups of achievement goals that reflect different criteria by which individuals evaluate their competence and define the success (or failure) of their participation in a given activity. Thus, competence "plays a central role in this theory" (Nicholls 1984, p. 343), being forms of achievement key elements of conceiving and judging success.

According to some authors (Duda 20,013; Roberts, 20,012), achievement goals can be measured in the sport context, in which individuals guide their goals of accomplishment in two distinct forms, resulting in differentiating consequences. Task-oriented individuals perceive their competence in terms of self-evaluative standards or task mastery (i.e., the judgment of competence is carried out through a process of comparison with the self). Hence, task-oriented individuals tend to engage in adaptive behavior strategies (e.g., they try harder, choose challenging tasks, or are more persistent on the behavior). On the other hand, ego-orientation reflects competence perception based on one's attainment or doing better than others (e.g., peers, opponents). In this regard, ego-oriented individuals put more emphasis on winning as opposed to developing skills, adopting mal-adaptive behaviors (e.g., less persistent in carrying out hard challenges, less commitment to the activity, or greater levels of anxiety in performing a given behavior) as stated by past literature (Duda 2013, 2001).

AGT has been applied to the context of sport and physical education over the last years (Roberts 2001, 2012; Treasure 2001; Treasure \& Roberts, 1995). However, in the past decades it began to receive considerable amount of attention from the scientific literature in the field of physical activity and exercise (Duda 2013; Kilpatrick et al. 2003; Petherick and Markland 2008). Additionally, its relevance and applicability in the exercise context is still a topic of debate among researchers regarding theoretical aspects and practical issues (Roberts 2012; Stevenson and Lochbaum 2008).

As stated by Kilpatrick et al. (2003), both the sport and exercise domains provide practitioners with the opportunity to assess their achievement of accomplishing goals and defining success and competence. As such, it is likely that the behavior in both contexts can be influenced consistently by the perspective of realizing achievement goals.

It is reasonable to assume that most people engage in physical exercise with a predominantly task-orientated manner (e.g., increasing skills and physical fitness). However, we cannot rule out the possibility that people engage in this context for ego-orientated reasons (e.g., lifting more weights than others). This stems from the notion that human beings are somehow forced to make interpersonal comparisons and this happens naturally in different aspects (see Social Comparison Theory; Festinger 1954).

According to Petherick e Markland (2008), the main issue on the application of AGT in the exercise context has been the defining process of achievement, which competition and the demonstration of competence is not directly expressed in this domain. However, literature has shown that exercisers display different reasons for their involvement with exercise practice, which can both reflect the aspects associated with personal improvement, as well as competitive aspects such as social recognition (e.g., Markland and Ingledew 1997; Rodrigues et al. 2019). For this reason, Kilpatrick et al. (2003) argue individuals can experience ego-orientation, having a significant impact on 
exercise participation. These results are supported by Rodrigues et al. (2019) in a study conducted with three independent samples of exercisers, in which participants are able to define success and/or engage in physical activity based on normative comparisons.

\subsection{The measurement of achievement}

The ability to examine the applicability of achievement goal factors in the exercise context is contingent on the development of valid instruments. Hence, Kilpatrick et al. (2003) developed the Goal Orientation Exercise Scale (GOES), based on the Task and Ego Orientation in Sport Questionnaire (TEOSQ: Duda and Nicholls 1992), filling a crucial gap in the literature. However, although the development of such a measure is a commendable effort, the GOES presented several limitations as stated by Petherick e Markland (2008).

First, the GOES was developed based on the existing TEOSQ (Duda and Nicholls 1992), which has been criticized on the basis that the task factor blurs the definition of task orientation (i.e., perception of self-referenced competence) with its correlates (e.g., effort, learning, enjoyment). Given that theoretically task and ego-orientations are orthogonal (i.e., may not be correlated), this suggests that ego-oriented individuals do not experience such self-referenced competence, which may not be true. It is very likely that ego-oriented individuals may also experience enjoyment during exercise as long as their conception of achievement is achieved (i.e., demonstration of competence). On the other hand, it is also possible that task-oriented individuals respond favorably to items related to normative competence, which can reduce the sensitivity of differentiation of both achievement goal orientations.

A more careful analysis of the TEOSQ reveals that the definition of task-orientation is explored by feelings of success associated with learning, effort and enjoyment; whereas, ego-orientation evaluation depends on responses associated only with normative criteria of success (Harwood et al. 2000; Harwood et al. 2003). Harwood and colleagues (2003, 2000) state that, if we want to correctly evaluate the contents of both subscales concerning the characterization of self-referenced mastery and normative superiority, then all assumptions related to correlates must be removed.

Related to this matter, even though Petherick and Markland (2008) made the critique on the GOES, these authors did developed together the initial pool of items in the Goal Orientation in Exercise Measure (GOEM; 21 items) based on the GOES (Kilpatrick et al. 2003) and on the TEOSQ measure (Duda and Nicholls 1992). Although most of the confusing items were removed and submitted to a evaluation of a panel of four exercise psychologists, there are other instruments that also have been used on creating the GOEM, like the Perception of Success Questionnaire (POSQ: Roberts et al. 1998; Treasure and Roberts 1994). In this measure, although the task and ego items share some common characteristics, the evaluation of task-orientation achievement is less ambiguous and more balanced than the TEOSQ subscale (Harwood et al. 2000), focusing less on correlates and more on self-referenced aspects (e.g., performance, skills). Additionally, the authors of the GOES did not specified which statement should precede each item, suggesting using the TEOSQ statement ("I feel most successful in sport when...") with the appropriate adaptations to the exercise. In this sense, the relevance of applying the term "success" to the exercise context can be called into question, since it originally implies the notion of victory (winning), which seems to be more oriented as a competitive norm. Last, even if the authors of the GOES suggest that they only included gym exercisers (i.e., aerobic activities and resistance training) in the study, this situation is not clear, since when asking individuals if 
exercise participation was part of a training regime for competitive reasons, approximately $30 \%$ of participants answered yes. This fact can cause misperception in the assessment of the achievement goals in the exercise context.

On this issue of participant recruitment, if we look carefully at the characterization of the participants in the study of Kilpatrick et al. (2003), the reported data reflect some inconsistencies regarding the context in which the GOES was applied: $32 \%$ had no exercise experience or were recreational practitioners; $36 \%$ were endorsed in high school sports activities; $12 \%$ were participants in college physical activities; and, $9 \%$ participated in interschool sports activities. All in all, the application of the GOES does not seem to be clearly outlined about the exercise domains' perspective of achievement.

Considering previous literature, Petherick and Markland (2008) developed a new instrument, overcoming the limitations of the GOES. According to these authors, the GOEM, a 10-item measure grouped into two factors (five items each), seems to be a more robust scale both in conceptual and in statistical terms. In fact, the results showed acceptable measurement model fit, was well as internal consistency coefficients $\left(\alpha_{\text {Ego }}=0.88\right.$; $\alpha_{\text {Task }}=0.78$ ). According Petherick and Markland (2008), factor loadings of the GOEM were adequate ranging between 0.56 and 0.90 , and the model also revealed to be invariant between gender. Additionally, the GOEM was validated in a sample of 372 exercisers from different gym and health clubs. Despite the fact that some participants of the sample were sport practitioners (e.g., martial arts, racquet sports, soccer), the authors reinforced the recreational nature of the activities, ensuring that these individuals only practiced them for reasons of improving or maintaining their physical fitness. A recent study developed by Ersöz et al. (2017) analyzing achievement goals orientation in 408 Turkish gym exercisers, support the results of the original version, demonstrating that the measurement model of the GOEM had acceptable fit to the data, also demonstrating predictive validity criteria with the distinct forms of motivation based on Self-Determination Theory (SDT; Ryan and Deci 2017). This means that task-orientation was regarded as being positively associated with autonomous forms of motivation; whereas ego-orientation presented a positive correlation with controlled forms of motivation. Nevertheless, the study developed by Ersöz et al. (2017) did not demonstrate invariance criteria between genders or different fitness activities, having been pointed out by the authors as a limitation, suggesting that future studies should carry out this analysis in forthcoming studies.

\subsection{Current study}

The present study aimed to translate and validate the GOEM (Petherick and Markland 2008) in a sample of Portuguese exercisers. Confirmatory factor analysis and multigroup analysis between genders will be performed to examine the psychometric properties of the factor structure, and to examine measurement invariance, respectively. Bearing in mind previous validation studies (Petherick and Markland 2008; Ersöz et al. 2017) we hypothesized that: (a) the measurement model of the GOEM Portuguese version would display acceptable fit to all samples under analysis; (b) considering the original research of the GOEM (Petherick and Markland 2008), we hypothesize that the measurement model will be invariant between male and female exercisers, as well across fitness activities including resistance training, cardio workout, and fitness group classes..

Predictive validity of the task and ego-orientations factors were put to test on their predictive power on motivational factors based on the SDT framework (Ryan and Deci 2017), specifically those from the Organismic Integration Theory (OIT; Deci and Ryan 2000), 
using structural equation modelling analysis. The OIT micro-theory within the SDT framework (Ryan and Deci 2017) explores the internalization and integration of the behavior. It is these two processes (internalization and integration) that allow extrinsically motivated behaviors to become more self-determined over time (Ryan and Deci 2017). Hence, considering previous evidence related to the AGT and SDT symbiosis in the exercise context (Petherick and Markland 2008; Ersöz et al. 2017), in the physical education context (Gómez-López et al. 2015; Standage and Treasure 2002; Wang et al. 2002), and in the sport domain (Almagro et al. 2015; Balaguer et al. 2011; Kesthidar and Behzania 2017), we speculate that: (a) task-orientation would be positively and significantly correlated with autonomous forms of motivation, and negatively with controlled forms of motivation; and, (b) ego-orientation would be positively and significantly correlated with controlled forms of motivation, and negatively with autonomous forms of motivation.

\section{Methods}

\subsection{Participants}

In this cross-sectional design study, a total of 550 exercisers (female $=264 ; M_{\text {age }}$ 30.03 years, $\mathrm{SD}=10.20$ ) from different gym and health clubs were considered for assessment. Exercisers where engaged in different fitness activities, namely: resistance training $(n=144)$, fitness group classes $(n=175)$, and cardio workout $(n=231)$. Training sessions lasted between 1 and 15 hours per week $(M=4.95 ; \mathrm{SD}=2.37)$, mean attendance was 3.06 sessions $(\mathrm{SD}=1.08)$ per week, and mean exercise experience was 37.63 months $(\mathrm{SD}=2.37)$.

\subsection{Procedures: data collection}

All data collection procedures were in accordance with the ethical standards of the institutional research committee and with the 1964 Helsinki declaration and its later amendments or comparable ethical standards. Approval for this study was granted by the Research Center in Sports Sciences, Health Sciences and Human Development (CIDESD), institution that is registered in the Portuguese National Science Foundation (FCT) under the reference UID/DTP/04045/2019. Next, several gym and health club managers were contacted and briefed about the objectives of the study. After approval, potential participants were approached at reception desk and asked to participate voluntarily in this study. Then, they were asked to read a brief information note and complete a consent form. Informed consent was obtained from all individual participants included in the study before completing the survey. The survey took approximately 10 minutes to completion.

\subsection{Instruments}

The Goal Orientation Exercise Measure (GOEM; Petherick and Markland 2008) was used to measure goal orientations. This two-dimensional ten item instrument assesses the extent to which respondents define success in terms of task (five items: e.g., "I exercise to the best of my ability") and ego (five items: e.g., "I prove to myself that I am the only one who can do a certain exercise task") according to the AGT framework (Nicholls 1984, 1989). Participants provided responses using a five-point scale anchored from strongly disagree (1) to 
strongly agree (5). Previous studies (e.g., Petherick and Markland 2008) provide acceptable reliability of each sub-scale $\left(\alpha_{\text {task }}=0.78 ; \alpha_{\text {ego }}=0.88\right)$.

For the present study, the GOEM was translated following Brislin (1980) recommendations using the committee approach translation methodology. This procedure has been used in previous literature and endorsed by several authors, since it represents an improvement in the evaluation-quality of the semantic aspects of the instruments from one language to another (Fonseca and Brito 2005). Additionally, this approach has the advantage of allowing committee members to more easily detect possible errors inherent in the translation process, through cooperation within each individual's expertise (Geisinger 2003). Hence, after granting approval from one of the original authors (Caroline Petherick), the translation process was developed in five stages, from the initial translation to the final version: preliminary translation; first evaluation panel in which the initial Portuguese version was reviewed by four specialists; second evaluation panel in which the new Portuguese version was evaluated by a different panel of four other specialists; pilot study in which the GOEM was administered to bilingual college students; and, final version was created after syntax, spelling, and grammar check.

The Behavioral Regulation in Exercise Questionnaire (BREQ-2; Markland and Tobin 2004-Portuguese version Cid et al. 2012) was used to measure how individuals regulate their behavior towards exercise. This 19-item instrument assesses: amotivation (four items: e.g., "I do not know why I still exercise"), external regulation (four items: e.g., "I exercise because other people tell me I have to"), introjected regulation (three items: e.g., "I feel guilty when I skip an exercise session"), identified regulation (four items: e.g., "I value exercise and I get restless if I do not exercise regularly") and intrinsic motivation (four items: "I exercise because it is fun"), based on SDT (Ryan and Deci 2017). Participants provided responses using a five-point scale anchored from strongly disagree (0) to strongly agree (4). Markland and Tobin (2004) have shown this instrument to provide acceptable reliability were coefficients ranged from 0.73 (identified regulation) to 0.86 (intrinsic motivation).

\subsection{Statistical analysis}

A preliminary analysis of the data was performed to verify normal distribution of the data and to examine possible missing values and outliers (Mahalanobis distance). Pearson bivariate correlations were calculated to determine the test-retest reliability of participants' responses on the items.

For test-retest analysis, 40 Portuguese exercisers were recruited based on the probability theory, in which a sample size greater than or equal to 30 comes close to a normal distribution (Hair et al. 2019). The interval between survey administrations was four weeks as proposed by Vallerand (1989).

The factor structure of the GOEM was examined using a Confirmatory Factor Analysis (CFA) as proposed by several authors (Kline 2016; Hair et al. 2019). Analysis on the factor structure of the GOEM was performed using IBM SPSS AMOS 23.0 (Arbuckle 2014) and estimates calculated using the Maximum Likelihood (ML) estimator. Concerning sample size, current sample was above the 10:1 ratio (10 participants for each parameter to be estimated) as suggested by Kline (2016). A Structural Equation Modelling (SEM) was performed to test for predictive validity, considering behavioral regulations as dependent variables. 
In order to assess CFA and SEM model fit, the following traditional and incremental indexes were considered: Comparative Fit Index (CFI); Tucker-Lewis Index (TLI); Standardized Root Mean Square Residual (SRMR) and Root Mean Square Error of Approximation (RMSEA) with a 90\% Confidence Interval (CI90\%). For these indexes, the following cutoffs were considered (Byrne 2016; Hair et al. 2019; Kline 2016; Marsh et al. 2004): CFI and TLI $\geq 0.90$; SRMR and RMSEA $\leq 0.80$. To evaluate convergent validity, Average Variance Extracted (AVE) was calculated considering scores $\geq 0.50$ as acceptable (Hair et al. 2019). Discriminant validity was established when the AVE score for each factor exceeded the squared correlation between that and any other factor (Hair et al. 2019). Internal consistency was examined considering composite reliability coefficients accepting values $\geq 0.70$ (Raykov et al. 2015; Raykov 1997).

A multigroup analysis was conducted in order to ensure measurement invariance of the GOEM between gender and across fitness activities, including resistance training, cardio workout, and fitness group classes. Thus, several recommendations were considered (Byrne 2016; Chen 2007; Cheung and Rensvold 2002), namely: (a) the measurement model should present acceptable fit in each sample; (b) the configural, metric, scalar and residual invariance criteria should be respected. The invariance assumptions were verified through the following criteria: differences $(\Delta)$ in $\mathrm{CFI} \leq 0.01$, RMSEA $\leq 0.015$ or $\mathrm{SRMR} \leq 0.030$ for scalar invariance; $\mathrm{CFI} \leq 0.01$; RMSEA $\leq 0.015$ and $\mathrm{SRMR} \leq 0.010$ for metric and residual invariance.

\section{Results}

\subsection{Preliminary analysis}

An inspection of the data revealed no missing values, and no univariate outliers were detected. Task-orientation presented a higher mean compared to ego-orientation. Results revealed no violations of data distribution since skewness and kurtosis values were comprised within cutoffs. The correlation matrix presented significant associations as theoretically expected: (i) task-orientation was positively and significantly correlated with autonomous forms of motivation, and negatively with controlled forms of motivation; and, (ii) ego-orientation was positively and significantly correlated with controlled forms of motivation, and negatively with autonomous forms of motivation.

Table 1 Descriptive statistics, composite reliability scores and correlation matrix across factors

\begin{tabular}{lrrrrrrrrrrr}
\hline Factor & M & SD & CR & AVE & 1 & 2 & 3 & 4 & 5 & 6 & 7 \\
\hline 1.Task & 4.19 & .46 & .78 & .43 & 1 & - & - & - & - & - & - \\
2.Ego & 1.92 & .79 & .90 & .65 & .07 & 1 & - & - & - & - & - \\
3.Amotivation & .23 & .54 & .72 & - & $-.11^{* *}$ & $.33^{* *}$ & 1 & - & - & - & - \\
4.External Regulation & .39 & .71 & .80 & - & $-.09^{*}$ & $.31^{* *}$ & $.56^{* *}$ & 1 & - & - & - \\
5.Introjected Regulation & 1.38 & .92 & .73 & - & $.12^{* *}$ & $.09^{*}$ & $.23^{* *}$ & $.34 * *$ & 1 & - & - \\
6.Identified Regulation & 3.02 & .65 & .74 & - & $.28^{* *}$ & $-.08^{*}$ & $-.15^{* *}$ & .01 & $.37 * *$ & 1 & - \\
7.Intrinsic Motivation & 3.31 & .68 & .70 & - & $.30^{* *}$ & $-.10^{*}$ & $-.18^{* *}$ & $-.10^{*}$ & .06 & $.52^{* *}$ & 1 \\
\hline
\end{tabular}

$\mathrm{M}=$ mean; $\mathrm{SD}=$ standard deviation; $\mathrm{CR}=$ composite reliability; $\mathrm{AVE}=$ average variance extracted; $* p \leq$ $0.05 * * p \leq 0.001$ 
Composite reliability coefficients were above acceptable presenting internal consistency. AVE scores were acceptable for the ego-orientation factor but not for the task-orientation factor. However, since all factors loaded significantly the respective factors, items were maintained in both achievement goal factors. Additionally, no problems of discriminant validity were found, presenting themselves as distinct factors $\left(\mathrm{R}^{2}=0.001\right)$. For more details see Table 1.

\subsection{Test-retest analysis}

Concerning to test-retest analysis (see Table 2), Pearson's correlations from responses given to each item in the first and second administrations of the questionnaire ranged from 0.77 (Item 4) to 0.87 (Item 2). Thus, test-retest correlations were considered as acceptable $(>0.70)$, indicating that the items comprised in the GOEM had a high degree of temporal reliability.

\subsection{Factor structure}

The Mardia coefficient for multivariate kurtosis exceeded the recommended value in all samples under analysis $(<5)$, Therefore, a Bollen-Stine Bootstraps of 2000 sample was inserted in posterior analysis (Nevitt and Hancock 2001). Possible collinearity issues were diagnoses using the Variance Inflation Factor (VIF) and the tolerance test. Results showed that both the VIF test and tolerance test scores were below 10 and above 0.1 , respectively, ensuring the appropriate conditions to test the regression model. Results from the CFA provided support to the original two-factor model of the GOEM in all samples as seen in Table 3. Additionally, looking at Fig. 1 considering total sample, it is possible to examine that all factor loadings explained at least $25 \%$ of the latent factor variance.

Table 2 Test-retest reliability analysis

\begin{tabular}{llll}
\hline Items & $\mathrm{M} \pm \mathrm{SD}$ & $r$ & $p$ \\
\hline Item1 pre-post & $4.30 \pm 0.56-4.33 \pm 0.57$ & 0.80 & $<.001$ \\
Item2 pre-post & $2.13 \pm 0.88-2.23 \pm 0.73$ & 0.87 & $<.001$ \\
Item3 pre-post & $4.43 \pm 0.50-4.38 \pm 0.49$ & 0.80 & $<.001$ \\
Item4 pre-post & $4.22 \pm 0.53-4.15 \pm 0.48$ & 0.77 & $<.001$ \\
Item5 pre-post & $2.05 \pm 0.85-2.08 \pm 0.86$ & 0.84 & $<.001$ \\
Item6 pre-post & $4.33 \pm 0.47-4.25 \pm 0.44$ & 0.83 & $<.001$ \\
Item7 pre-post & $2.15 \pm 0.95-2.13 \pm 0.88$ & 0.84 & $<.001$ \\
Item8 pre-post & $2.23 \pm 0.83-2.08 \pm 0.86$ & 0.80 & $<.001$ \\
Item9 pre-post & $4.18 \pm 0.50-4.13 \pm 0.46$ & 0.79 & $<.001$ \\
Item10 pre-post & $2.00 \pm 0.88-1.98 \pm 0.86$ & 0.85 & $<.001$ \\
Factor ego pre-post & $2.11 \pm 0.74-2.10 \pm 0.73$ & 0.90 & $<.001$ \\
Factor task pre-post & $4.29 \pm 0.37-4.25 \pm 0.35$ & 0.80 & $<.001$ \\
\hline$M=$ mean; SD=standard deviation; $r=$ correlation & coefficient; \\
P=level of significance at $\leq 0.001$ & &
\end{tabular}


Table 3 Psychometric properties of the GOEM

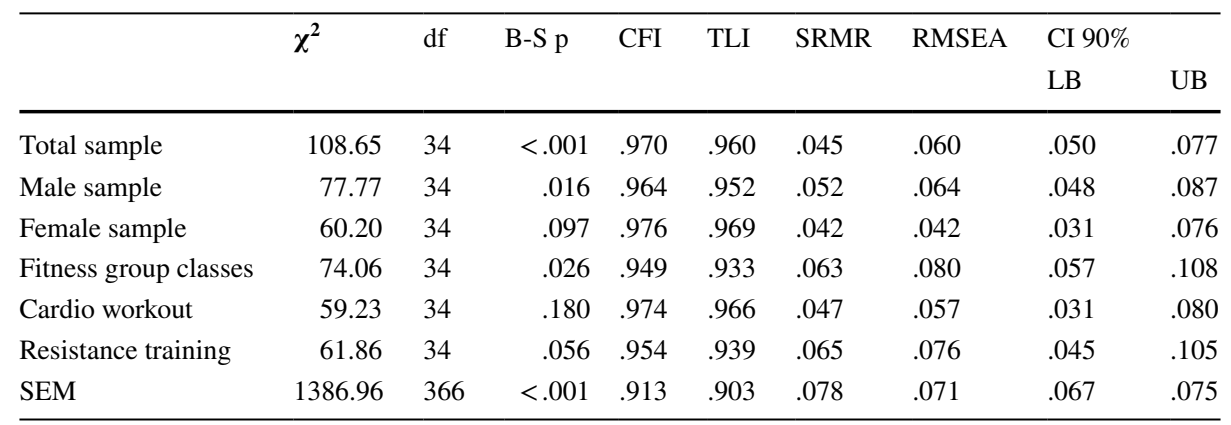

$\chi^{2}=$ chi-square; $\mathrm{df}=$ degrees of freedom; B-S $\mathrm{p}=$ bootstrap bollen-stine; $\mathrm{CFI}=$ comparative fit index; $\mathrm{TLI}=$ tucker lewis index; $\mathrm{SRMR}=$ standardized root mean square residual; RMSEA = root mean square error of approximation; $\mathrm{CI}=90=$ confidence interval of RMSEA; $\mathrm{LB}=$ lower bound; $\mathrm{UB}=$ upper bound

The SEM model displayed acceptable fit, moving forward to the analyses of the regression paths. The predictive validity analysis provided results as theoretically proposed: (i) task-orientation was a positive predictor of more autonomous forms of motivation, and a negative predictor of a motivation; and, (ii) ego-orientation was a positive and significant predictor of controlled forms of motivation, and negative predictor of identified regulation and intrinsic motivation. It is worth to mention that task-orientation positively and significantly predicted introjected regulation. For more details see Table 4.

\subsection{Multigroup analysis}

Results showed that the configural model fit the data well within samples (see Table 5). Next, the metric invariance model with the addition of identical factor loadings across samples, additionally provided adequate fit to the data. Then, item intercepts were constrained across samples and the model respected scalar invariance criteria. Last, the residual invariance criteria were respected, since item factor structure, factor loadings, item thresholds, and item residuals were equal between male and female, as well across fitness activities. Thus, based on the criterion adopted in the methodology for invariance procedures, results shown that the measurement model is invariant between genders and across aforementioned fitness activities, since all the invariance assumptions were achieved.

\section{Discussion}

The purpose of present study was to translate and validate the GOEM in a sample of Portuguese exercisers. Additionally, predictive validity of the task and ego-orientations factors were put to test on their predictive power on behavioral regulations based on the SDT framework (Ryan and Deci 2017). Last, measurement invariance analysis was conducted between genders to examine its applicability across groups with different characteristics. All in all, results from present study revealed that the original model of GOEM seems to 


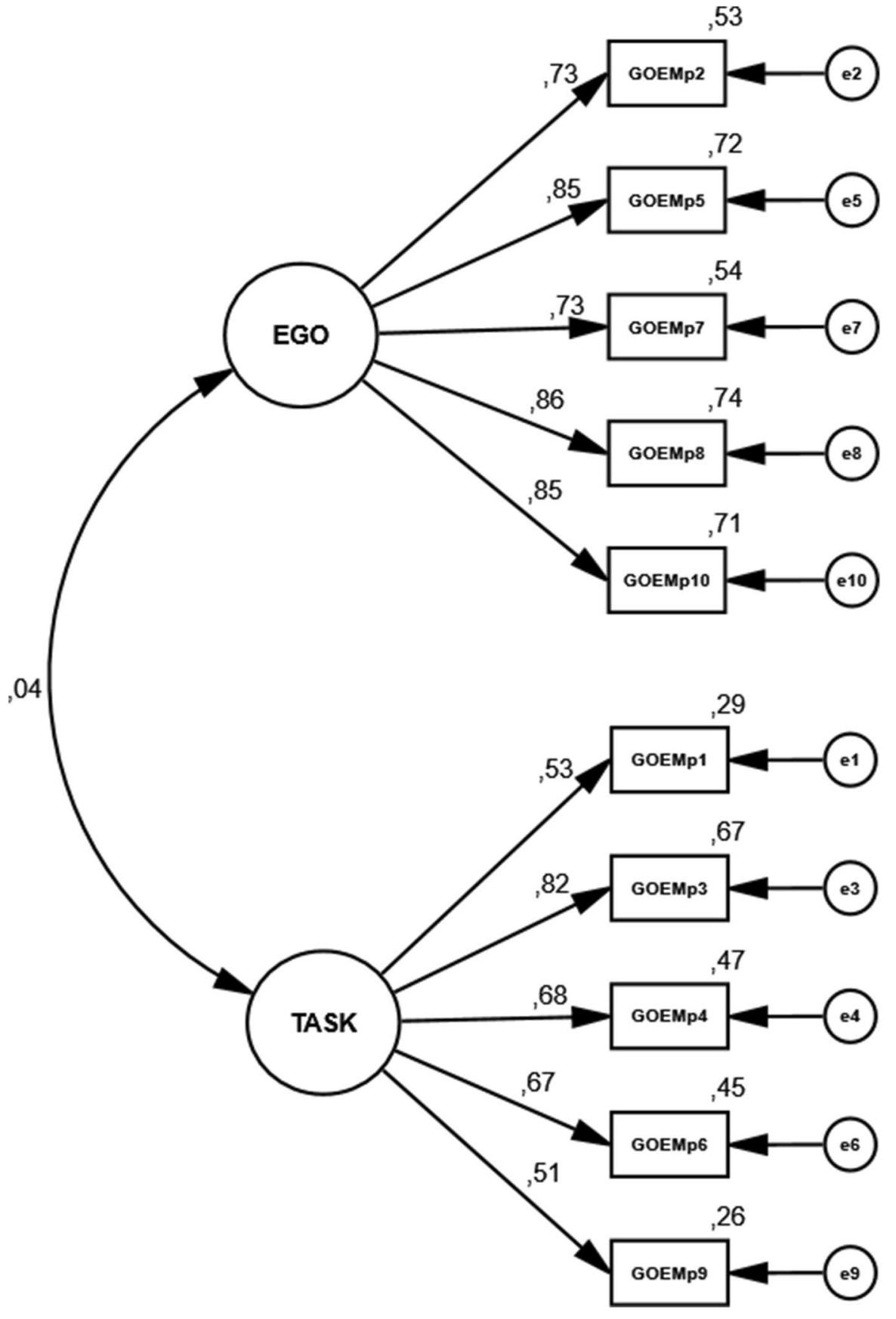

Fig. 1 Confirmatory factor analysis structure of the GOEM 
Table 4 Regression coefficients between achievement goals and behavioral regulations

\begin{tabular}{lccr}
\hline Path & $\beta$ & \multicolumn{2}{l}{ CI 95\% } \\
\cline { 3 - 4 } & & LB & UB \\
\hline Task $\rightarrow$ amotivation & -.21 & -.32 & -.09 \\
Task $\rightarrow$ external regulation & -.08 & -.20 & .03 \\
Task $\rightarrow$ introjected regulation & .20 & .00 & .35 \\
Task $\rightarrow$ identified regulation & .54 & .37 & .69 \\
Task $\rightarrow$ intrinsic motivation & .43 & .32 & .54 \\
Ego $\rightarrow$ amotivation & .46 & .33 & .59 \\
Ego $\rightarrow$ external regulation & .39 & .24 & .51 \\
Ego $\rightarrow$ introjected regulation & .13 & .02 & .31 \\
Ego $\rightarrow$ identified regulation & -.25 & -.41 & -.09 \\
Ego $\rightarrow$ intrinsic motivation & -.16 & -.26 & -.07 \\
\hline$\beta=$
\end{tabular}

$\beta=$ standardized coefficient; CI $95 \%=$ confidence interval at $95 \%$; $\mathrm{LB}=$ lower bound; $\mathrm{UB}=$ upper bound

Table 5 Multigroup analysis between gender

\begin{tabular}{|c|c|c|c|c|c|c|c|c|c|c|c|}
\hline Model & $\chi^{2}$ & $\Delta \chi^{2}$ & $\mathrm{df}$ & $\Delta \mathrm{df}$ & $p$ & $\mathrm{CFI}$ & $\Delta \mathrm{CFI}$ & SRMR & $\Delta$ SRMR & RMSEA & $\overline{\Delta R M S E A}$ \\
\hline \multicolumn{12}{|l|}{ M-F } \\
\hline Configural & 137.978 & - & 68 & - & - & .970 & - & .042 & - & .043 & - \\
\hline Metric & 161.883 & 23.905 & 78 & 10 & .008 & .964 & .006 & .049 & -.007 & .044 & -.001 \\
\hline Scalar & 161.930 & 23.952 & 79 & 11 & .013 & .964 & .006 & .049 & -.007 & .044 & -.001 \\
\hline $\begin{array}{l}\text { Residual } \\
\text { FGC—RT }\end{array}$ & 198.712 & 60.734 & 89 & 21 & $<.001$ & .953 & .017 & .047 & -.005 & .047 & -.004 \\
\hline Configural & 135.928 & - & 68 & - & - & .951 & - & .065 & - & .056 & - \\
\hline Metric & 147.619 & 11.691 & 78 & 10 & .306 & .951 & .000 & .068 & -.003 & .053 & .003 \\
\hline Scalar & 147.671 & 11.743 & 79 & 11 & .383 & .950 & .001 & .068 & -.003 & .052 & .004 \\
\hline $\begin{array}{l}\text { Residual } \\
\text { FGC-CW }\end{array}$ & 188.146 & 52.218 & 89 & 21 & $<.001$ & .929 & .022 & .067 & -.002 & .059 & -.003 \\
\hline Configural & 133.315 & - & 68 & - & - & .963 & - & .063 & - & .049 & - \\
\hline Metric & 143.723 & 10.408 & 78 & 10 & .405 & .963 & .000 & .066 & -.003 & .046 & .003 \\
\hline Scalar & 146.057 & 12.743 & 79 & 11 & .310 & .962 & .001 & .073 & -.010 & .046 & .003 \\
\hline $\begin{array}{l}\text { Residual } \\
\text { CW -RT }\end{array}$ & 155.650 & 22.335 & 89 & 21 & .380 & .962 & .001 & .078 & -.015 & .043 & .006 \\
\hline Configural & 121.130 & - & 68 & - & - & .967 & - & .065 & - & .046 & - \\
\hline Metric & 130.805 & 9.674 & 78 & 10 & .470 & .967 & .000 & .067 & -.002 & .043 & .003 \\
\hline Scalar & 132.605 & 11.475 & 79 & 11 & .404 & .966 & .001 & .074 & -.009 & .043 & .003 \\
\hline Residual & 163.533 & 42.403 & 89 & 21 & .004 & .953 & .014 & .078 & -.013 & .047 & -.001 \\
\hline
\end{tabular}

$\chi^{2}=$ chi-square; $\Delta \chi^{2}=$ differences in chi-square test; $\mathrm{df}=$ degrees of freedom; $\mathrm{p}=$ level of significance; $\mathrm{CFI}=$ comparative fit index; $\Delta \mathrm{CFI}=$ differences in comparative fit index; SRMR = standardized root mean square residual index; $\triangle \mathrm{SRMR}=$ differences in standardized root mean square residual; RMSEA $=$ root mean square error of approximation; $\triangle \mathrm{RMSEA}=$ differences in root mean square error of approximation index; $\mathrm{F}=$ Female; $\mathrm{M}=$ Male; $\mathrm{FGC}=$ Fitness Groups Classes; $\mathrm{CW}=$ Cardio Workout; $\mathrm{RT}=$ Resistance Training 
withhold acceptable consistency within a sample of Portuguese exercisers showing dimensionality on assessing achievement goal orientations.

\subsection{Factor structure}

Current results suggest that the original 10-item two-factor solution model assessing task and ego-orientations provided acceptable fit. Additionally, the GOEM Portuguese version, displayed acceptable fit in male and female exerciser samples, as well as in samples concerning different fitness activities. These results are indicative of supporting the use of the GOEM as a valid measure, as it has been examined in previous studies (Ersöz et al., 2017)

Concerning convergent validity, AVE scores were above cut-offs for the ego-orientation factor but not for the task-orientation factor, since the obtained value was below acceptable. However, all items loaded significantly their predefined factor, presenting also factor loadings above 0.50 , suggesting adequate convergent validity (Hair et al. 2019). Similar problems of convergent validity have been found in the original version (Petherick and Markland 2008). Thus, items were retained within the original 10-item measurement model, moving ahead to conduct discriminant validity analysis, as suggested by Byrne (2016) and Hair et al. (2019). Current analysis of the two-factor model displayed acceptable discriminant validity, since the squared correlation between task and ego-orientations was below the AVE, as suggested by the literature (Hair et al. 2014; Fornell and Larcker 1981). Additionally, the results also revealed that both factors showed adequate internal consistency since the composite reliability coefficients were greater than 0.70 (Hair et al. 2019).

The predictive validity criterion was achieved since the SEM model analysed did fit the data well and the associations across achievement goal orientations and behavioral regulations displayed results as theoretically proposed (Petherick and Markland 2008)., It seems that when exercisers are competence focused and thrive for increasing their physical fitness, they are likely to present a positive association with autonomous forms of motivation (i.e., identified regulation and intrinsic motivation) and a negative association with external regulation and amotivation. Contrarily, Portuguese exercisers who compete and consider their success and achievement based on doing better than others, they present a positive association with controlled motivation and amotivation and a negative association with autonomous motivation. These results align themselves with past literature (Balaguer et al. 2011; Ersöz et al. 2017; Wang et al. 2002; Petherick and Markland 2008), explaining the distinctiveness of achievement goal orientations and their prediction of motivation towards a given behavior.

All in all, the GOEM Portuguese version seems to present itself as a reliable source of measuring achievement goals in the exercise context. The Portuguese translated version supports the analysis conducted within the original instrument (Petherick and Markland 2008) as well as on other studies conducting with translated versions, like the Turkish version (Ersöz et al. 2017). Thus, current results indicate that task and ego-orientations are distinct factors, examining the views of Portuguese exercisers who drive for achievement when exercising, as recently demonstrated by Lochbaum et al. (2016). 


\subsection{Multigroup analysis}

Comparisons between gender and across different fitness activities assume that the same factors are measured equally. In the current study, the results supported configural, metric, scalar, and residual invariance criterion, as proposed by several authors (Byrne 2016; Hair et al. 2019). More specifically, the findings supported the original 10-item measurement model, with a two-factor dimensionality. As such, the 10-item model revealed that the participating Portuguese exercisers attribute the same meaning to the latent constructs. This provides empirical evidence supporting the use of the present GOEM in Portuguese exercisers with different characteristics.

\subsection{Limitations and agenda for future research}

Before concluding, there are some strengths in the present study that need to be acknowledged. First the reliance on the traditional CFA technique, permitting items to load on their predefined factors only, suppressing cross-loadings on unintended factors. Following from this, this technique allows researchers to estimate possible residual covariance, without compromising model specification (Hair et al. 2019).

Second, upcoming studies should conduct practical experiments manipulating achievement goal orientations to determine if similar results are obtained with or without intervention protocols. Experimental research should be used to determine casualeffect of task and ego orientations and their implications in several outcomes, such as intentions towards exercising in the future and adaptive emotional states (e.g., enjoyment, well-being).

Considering limitations of the present study, because of convenience sampling, we did not measure for intra-contextual equivalence. For example, multigroup analysis between different age groups was not possible because of the heterogeneity of age (range 18-69). Although this study was grounded on robust theoretical frameworks, personalcontextual characteristics should be measured in future research when conducting multigroup analysis as proposed by several authors (Ersöz et al. 2017; Rodrigues et al. 2019).

Last, this was the first attempt to translate and validate the GOEM into the Portuguese context, and to examine the factor structure of the instrument particularly in the exercise setting. Therefore, generalizations to other cultures or context must be made with caution, as more research is necessary to establish the dimensionality and validity of the instrument.

\section{Conclusion}

The GOEM Portuguese version seems to present itself as a reliable measure of task and ego orientations the exercise context. The 10-item measurement model solution produced acceptable results supporting the original factor structure model. Additionally, current results display measurement invariance between genders and across different fitness activities, showing is applicability in Portuguese exercisers with different characteristics. Thus, the GOEM version presents promising results for the use in future protocol interventions with the objective of assessing Portuguese exercisers' achievement goal orientations in light of the AGT framework. 
Funding Luis Cid and Diogo Monteiro were supported by national funds through the Portuguese Foundation for Science and Technology, I.P., under the project UID04045/2020/. Filipe Rodrigues was supported by the national funds through the Portuguese Foundation for Science and Technology, I.P., under the project UIDP/04748/2020.

\section{Compliance with ethical standards}

Conflict of interest They authors declare that they have no conflict of interst.

\section{References}

Arbuckle, J.L.: BM® SPSS® Amos ${ }^{\mathrm{TM}} 23$ User's Guide (2014).

Almargo, B., Bunuel, P., Moreno-Murcia, J., Spray, C.: Motivational factors in young spanish athletes: a qualitative focus drawing from self-determination theory and achivemente goal perspectives. Sport Psychol. 29, 15-28 (2015). https://doi.org/10.1123/tsp.2013-0045

Balaguer, I., Castillo, I., Duda, J., Garcia-Merita, M.: Associations between the perception of motivational climate created by coaches, dispositional goal orientations, forms of self-regulation and subjective vitality in young tennis players. Revista de Psicologia del Deporte 20(1), 133-148 (2011)

Brislin, R.: Translation and content analysis for oral and written material. In: Triandis, H., Berry, J. (eds.) Handbook of Cross-Cultural Psychology, vol. 2, pp. 389-444. Allyn and Bacon, Needham Heights, MA (1980)

Byrne, B.: Structural equation modeling with AMOS. Basic concepts, applications, and programming, 3rd edn. Taylor \& Francis Group, LLC., New York (2016)

Chen, F.: Sensitivity of goodness of fit indexes to lack of measurement invariance. Struct. Equ. Model. Multidiscpl. J. 14(3), 464-504 (2007). https://doi.org/10.1080/1070551070131834

Cheung, G., Rensvold, R.: Evaluating goodness-of-fit indexes for testing measurement invariance. Struct. Equ. Model. Multidiscpl. J. 9(2), 233-255 (2002). https://doi.org/10.1207/S15328007SEM0902_5

Deci, E., Ryan, R.: Self-determination theory and the facilitation of intrinsic motivation, social development, and well-being. Am. Psychol. 55(1), 68-78 (2000). https://doi. org/10.1037/0003-066X.55.1.68

Duda, J.: Achievement goal research in sport: Pushing the boundaries and clarifying some misunderstandings. In: Roberts, G. (ed.) Advances in Motivation in Sport and Exercise, pp. 129-182. Human Kinetics, Champaign-Illinois (2001)

Duda, J., Nicholls, J.: Dimensions of achievement motivation in schoolwork and sport. J. Educ. Psychol. 84, 290-299 (1992)

Duda, J.: The conceptual and empirical foundations of Empowering Coaching ${ }^{\mathrm{TM}}$ : Setting the stage for the PAPA project. Int. J. Sport Exerc. Psychol. 11(4), 311-318 (2013). https://doi.org/10.1080/16121 97X.2013.839414

Ersöz, G., Müftüler, M., Lapa, T.Y., Tümer, A.: Reliability and validity of goal orientation in exercise measure (GOEM)-Turkish version. Cogent Educ. 4, 1283877 (2017). https://doi. org/10.1080/2331186X.2017.1283877

Festinger, L.: A theory of social comparison processes. Hum. Relat. 7, 117-140 (1954)

Fonseca, A., Brito, A.: A questão da adaptação transcultural de instrumentos para avaliação psicológica em contextos desportivos nacionais - o caso do Task and Ego Orientation in Sport Questionnaire (TEOSQ). Psychologica 39, 95-118 (2005)

Fornell, C., Larcker, D.F.: Evaluating structural equation models with unobservable variables and measurement error. J. Mark. Res. 18(1), 39-50 (1981). https://doi.org/10.2307/3151312

Geisinger, K.: Testing and assessment in cross-cultural psychology. In: Graham, J., Naglieri, J. (eds.) Handbook of Psychology Assessment Psychology, pp. 95-117., Wiley, New Jersey (2003)

Gómez-López, M., Baena-Extremeral, A., Granero-Gallegos, A., Castañón-Rubio, I., Abraldes, J.A.: Self-determined, goal orientations and motivational climate in physical education. Colleg. Antropol. 39(1), 33-41 (2015)

Hair, J., Babin, B., Anderson, R., Black, W.: Multivariate Data Analysis, 8th edn. Pearson Educational, New Jersey (2019) 
Kline, R.: Principles and Practice of Structural Equation Modelling, 3rd edn. The Guildford Press, New York (2016)

Harwood, C., Hardy, L., Swain, A.: Achivement goals in sport: a critique of conceptual and measurement issues. J. Sport Exercise Psychol. 22, 235-255 (2000)

Harwood, C., Wilson, K., Hardy, L.: Achievement goals in sport: working towards an alternative model. J. Sport Sci. 21(4), 349-350 (2003)

Kesthtidar, M., Behzadnia, B.: Prediction of intention to continue sport in athlete students: a self-determination theory approach. PLoS ONE 12, 1-10 (2017). https://doi.org/10.1371/journal.pone.01716 73

Kilpatrick, M., Bartholomew, J., Riemer, H.: The measurement of goal orientations in exercise. J. Sport Behav. 26(2), 121-136 (2003)

Lochbaum, M., Çetinkolp, Z.K., Graham, K.A., Wright, T., Zazo, R.: Task and ego goal orientations in competitive sport: a quantitative review of the literature from 1989 to 2016 . Kinesiology 48(1), 3-29 (2016)

Markland, D., Ingledew, D.: The measurement of exercise motives. factorial validity and invariance across gender of a revised exercise motivation inventory. Br. J. Health. Psychol. 2, 361-376 (1997)

Markland, D., Tobin, V.: A modification to the behavioural regulation in exercise questionnaire to include an assessment of amotivation. J. Sport Exerc. Psychol. 26, 191-196 (2004). https://doi.org/10.1123/ jsep.26.2.191

Marsh, H., Hau, K., Wen, Z.: In search of golden rules: Comment on hypothesis-testing approaches to setting cutoff values for fit indexes and dangers in overgeneralizing $\mathrm{Hu}$ and Bentler's (1999) findings. Struct. Equ. Model. Multidiscpl. J. 11(3), 320-341 (2004)

Nevitt, J., Hancock, G.R.: Performance of bootstrapping approaches to model test statistics and parameter standard error estimation in structural equation modeling. Struct. Equ. Model. Multidiscpl. J. 8, 353377 (2001). https://doi.org/10.1207/S15328007SEM0803_2

Nicholls, J.: Achievement motivation: conceptions of ability, subjective experience, task choice, and performance. Psychol. Rev. 91(3), 328-346 (1984)

Nicholls, J.: The Competitive Ethos and Democratic Education. Harvard University Press, Cambridge (1989)

Pestana, M., Gageiro, J.: Análise de Dados para Ciências Sociais. a complementaridade do SPSS. Edições Sílabo, Lisboa (2005)

Petherick, C., Markland, D.: The development of a goal orientation in exercise measure (GOEM). Meas. Phys. Educ. Exerc. Sci. 12, 55-71 (2008)

Raykov, T.: Estimation of composite reliability for congeneric measures. Appl. Psychol. Meas. 21(2), 173184 (1997). https://doi.org/10.1177/01466216970212006

Raykov, T., Gabler, S., Dimitrov, D.: Maximal reliability and composite reliability: examining their difference for multicomponent measuring instruments using latent variable modeling. Struct. Equ. Model. Multidiscipl. J. 23(3), 384-391 (2015). https://doi.org/10.1080/10705511.2014.966369

Roberts, G.: Motivation in sport and exercise from an achievement goal theory perspective: after 30 years, where are we? In: Roberts, G., Treasure, D. (eds.) Advances in Motivation in Sport and Exercise, pp. 5-58. Human Kinetics, Champaign, IL (2012)

Roberts, G.: Achivement motivation in children's sport. In: Nicholls, J. (ed.) Advances in Motivation and Achievement. The Development of Achievement Motivation. JAI Press Inc, Greenwich (1984)

Roberts, G.: Understanding motivation. In: Roberts, G. (ed.) Motivation in Sport and Exercise, pp. 3-29. Human Kinetics, Champaign, Illinois (1992)

Roberts, G.: Understanding the dynamics of motivation in physical activity: the influence of achievement goals on motivational processes. In: Roberts, G. (ed.) Advances in Motivation in Sport and Exercise, pp. 1-50. Human Kinetics, Champaign-Illinois (2001)

Roberts, G., Treasure, D., Balaguer, G.: Achievement goals in sport: the development and validation of the Perception of Success Questionnaire. J. Sport Sci. 16, 337-347 (1998)

Rodrigues, F., Moutão, J., Teixeira, D.S., Cid, L., Monteiro, D.: Examining exercise motives between gender, age and activity: a first-order scale analysis and measurement invariance. Curr. Psychol. (2019). https://doi.org/10.1007/s12144-019-00560-y

Ryan, R., Deci, E.: Self-Determination Theory Basic Psychological Needs in Motivation, Development and Wellness. The Guilford Press, New York (2017)

Standage, M., Treasure, D.C.: Relationships among achievement goal orientations and multidimensional situational motivation in physical education. Br. J. Educ. Psychol. 72, 87-103 (2002)

Stevenson, S.J., Lochbaum, M.: Understanding exercising motivation: examining the revised social-cognitive model of achievement motivation. J. Sport Behv. 31(4), 389-412 (2008) 
Treasure, D.: Enhancing young people's motivation in youth sport: an achievement goal approach. In: Roberts, G. (ed.) Advances in Motivation in Sport and Exercise, pp. 79-100. Human Kinetics, Champaign (2001)

Treasure, D., Roberts, G.: Perception of success questionnaire: preliminary validation in an adolescent population. Percept. Mot. Skills 79, 607-610 (1994)

Treasure, D., Roberts, G.: Applications of achievement goal theory to physical education: implications for enhancing motivation. Quest 47, 475-489 (1995)

Vallerand, R.: Vers une méthodologie de validation transculturelle de questionnaires psychologiques: implications pour la recherche en langue française. Can. Psychol. 30(4), 662-680 (1989)

Wang, C.K.J., Chatzisarantis, N.L.D., Spray, C.M., Biddle, S.J.H.: Achievement goal profiles in school physical education: differences in self-determination, sport ability beliefs, and phsyical activity. Br. J. Educ. Psychol. 72, 433-445 (2002)

Publisher's Note Springer Nature remains neutral with regard to jurisdictional claims in published maps and institutional affiliations. 